DOSSIÊ JOSÉ SARAMAGO 


\section{Apontamentos sobre a cidade saramaguiana}

Horácio Costa

Universidade de São Paulo

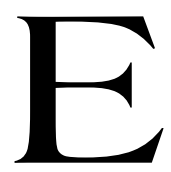

ste texto nasce de uma maneira espontânea: apontamentos para um possível desenvolvimento ulterior. Feitos por quem já, no passado, intentou uma leitura estruturada do autor que os desperta, aqui se aponta um nó irradiante para uma leitura alterna. No mar aberto da literatura, um autor-maior escreve obras que zarpam ao longo do tempo em total liberdade; o que segue não almeja mais do que ser um portulano para navegar um aspecto da obra saramaguiana. Por força do que acaba de ser dito, estes apontamentos surgem numerados em aparente ordem, que mascara o fato de que entre eles não há um cerzimento retórico absolutizante que os disponha tal e como se oferecem; em resumo, entre eles, desde um princípio, está abolido o horizonte da hierarquia do dizer. Que um puxe o outro, que se abram aos ventos, e comecemos.

1. José Saramago tem um caso de amor-ódio - ou de amordesamor, ou, ainda, de aceitação-recusa - para com a cidade, que se espraia ao longo de sua obra. A afirmação é quiçá demasiado taxante e necessita ser matizada. Explico. Para tanto, nada melhor do que a divisão em famílas tipológicas, por um lado, e a posta em cena do recurso ou da tentação genética, por outro, sempre considerando a totalidade de sua obra. Vamos lá.

1.1. Antes de mais nada, houve e há Lisboa, ainda que, como disse Pessoa, ninguém possa provar que ela esteja aonde sempre esteve, nem nenhuma outra coisa, for that matter. Sendo ou não artigo de fé, Lisboa permeia os textos saramaguianos desde os seus 
livros de crônicas, pelo menos (façamos exceção a alguns poemas de Ospoemas possíveis, nos quais a sensibilidade para com o urbano se transparenta). Sobre os seus livros de poesia o autor disse, quando da sua re-edição, que neles se encontravam "nexos, temas e obsessões" que a sua obra futura desenvolveria. Pois bem, tal ponto de vista (auto)crítico vale não só para os poemas, mas também - e quiçá principalmente - para as crônicas: nelas, sim, muito do que depois escreveu está in nuce, e entre outras coisas obvia-se a sensibilidade para com o fato urbano lisboeta.

1.2. Consideremos tão só uma crônica, "Travessa de André Valente", de Deste mundo e do outro. Nela, o cronista encontra-se com o fantasma de Bocage, e tem com o poeta uma conversa peripatética que se desenrola no cenário da Lisboa histórica. Mais exatamente pelo Bairro Alto e seus arredores, a começar pelo encontro fortuito que se dá junto à casa na qual morou Bocage, na dita travessa. Não importa a situação literária em si, fruto de uma evocação talvez freqüente de viandante acostumado a um percurso, mas sim o trecho no qual Saramago transmite ao leitor a sua surpresa pelo fato de que a paisagem na qual ele se encontra não ser a mesma que vê o fantasma:

Subimos a Rua do Século, e andando chegamos ao Jardim de Santa Catarina. Íamos ver navios. Simplesmente, os navios não eram os mesmos, e quando descobrimos que estávamos a falar de coisas diferentes, largámos a rir. [...] Depois, o Bocage começou a dizer versos [...] que eu sabia nascidos naquele momento daquela madrugada. Mas que madrugada? A minha ou a dele? Percebi então que um de nós era um fantasma. Do passado ou do futuro - ele, ou eu.

Este encontro se oferece à interpretação de várias maneiras: por exemplo a literal-textual, como exercício imaginante, uma outra, entre tantas, como certificação de cidadania imaginária de quem o escreve. Tão cheio está o tecido urbano de ecos, de vozes, de presenças, como para Saramago o de Lisboa, que a habitabilidade dele é plenamente real-imaginária, como que táctil para o cronista. 
1.3. Lisboa, a cidade evanescente, torna-se assim real num continuum que desconhece a fronteira espácio-temporal. Nada melhor, entretanto, para cifrar esta equação, que a presença magnetizadora do arqui-poeta no Largo Camões, em seu indiferente pedestal, à qual constantemente levam as deambulações do heterônimo pessoano apud Saramago em O ano da morte de Ricardo Reis. Esta referência espacial e simbólica atravessa toda a literatura portuguesa moderna: é ao pé da estátua que o Padre Amaro, o Cônego Dias e o Conde de Ribamar encontram-se e entretêm a significantíssima conversação ao final da segunda escritura do primeiro romance de Eça; ainda, lembremo-nos apenas que "O sentimento de um ocidental" refere-se a ela, com tudo o que implica no imaginário coletivo lusitano, numa passagem da maior importância, e que revela o quanto a presença do poeta ronda a imaginação dos seus sucessores, em Portugal:

E evoco, então, as crónicas navais:

Mouros, baixéis, heróis, tudo ressucitado!

Luta Camões no Sul, salvando um livro a nado!

Singram soberbas naus que eu não verei jamais!

(...)

Mas num recinto público e vulgar,

Com bancos de namoro e exíguas pimenteiras,

Brônzeo, monumental, de proporções guerreiras,

Um épico doutrora ascende, num pilar!

("O sentimento...." I-6 e II-6)

Camões ronda e ronda, quase que ameaçadoramente, congelado na atitude que lhe moldaram no século XIX, e como que fazendo jus à teoria da "anxiety of influence" de Harold Bloom. Verdade seja dita: na citação anterior, juntei estrofes de partes diferentes; quem sabe não seria o "épico doutrora” D. João I, quem cavalga sua estátua incolumemente, num logradouro que, de modo improvável, chama-se ou chamava-se Largo da Figueira?

1.4. Sem dúvida, o momento supremo desta habitabilidade no tempo histórico lisboeta por parte de Saramago se dá nos livros nos 
quais a matéria histórica é mais importante, respondendo pela estrutura mesma do relato, como em Memorial do convento e História do cerco de Lisboa. Digamos que ambos romances oferecem suas respectivas arqueologias ao leitor, uma vez que, infere-se, ninguém pode escrever uma narração eivada pela matéria histórica sem pesquisá-la e, o que é tão importanto quanto, entendê-la. Assim, a Escola de Escultura de Mafra e a reconstrução de Lisboa depois do terremoto, capítulos da arte portuguesa estudados por um Ayres de Carvalho e um José Augusto França, por exemplo, em obras que marcaram época, ainda que não estejam lá, na fábrica textual, se transparentam nos detalhes da sua andaimaria, tanto quanto, digase de passagem, e com maior nitidez, as informações dos cronistas da época que, como já tive a oportunidade de apontar em meu estudo José Saramago: o período formativo, respondem mesmo por certas situações ou personagens-chave (como a de Blimunda, no caso de Memorial do convento). ${ }^{1}$

Detrás dessas operações, está Lisboa, seus momentos e humanidades, seus avatares e transformações. Saramago caminha por e para Lisboa, no duplo sentido do "para": em direção a e como se num ritual de acasalamento, mostrando as suas plumas, os seus rituais encantatórios. Baltasar e Blimunda, Mogueime e Ouroana, o sr. Raimundo Benvindo da Silva e Maria Sara - isto, sem falar no "par original" dos amores saramaguianos, as personagens H. e M. do Manual de pintura e caligrafia-, todos têm em comum a personagem Lisboa, em diferentes estágios de seu desenvolvimento histórico e imaginário, não apenas como a confidente de fundo, como testemunha de eleição de seus respectivos impulsos amorosos, mas também como a receptora imóvel e, ainda assim, se se pode dizer, não passiva deles. Em resumo, para lá dos estilemas, que nos remetem tanto à atividade escritural de Saramago que se desenvolve em auto-variações e auto-intertextualidades, como aos "nexos, temas

${ }^{1}$ Cf. nota 20 ao cap. VII (A reconquista da prosa: Manual de pintura $e$ caligrafia e Objecto Quase). In: COSTA, 1997. p. 316-317. 
e obsessões" de sua origem como escritor, está também Lisboa, a insondável e a iluminada, que se reescreve a si mesma através da linhagem de seus filhos que escrevem, à qual pertence, com muita honra, José Saramago.

1.5. À guisa de ilustração do que acaba de ser dito, confiramos um trecho de História do cerco de Lisboa:

(...) A chuva ressoa surdamente no zinco do alpendre, e ele não a ouve, (...) é como um rumor ainda longínqüo de cavalgada, um bater de cascos na terra branda e húmida, (...) estranho sucesso este, se no inverno sempre se suspendiam as guerras, que seria dos homens de cavalo, (...) com as mãos tão engadanhadas de frio que mal podem segurar as armas diminutas com que vêm a conquistar Lisboa, que lembrança a do rei, vir à guerra com este mau tempo, Mas o cerco foi no verão, murmurou Raimundo Benvindo da Silva. A chuva no alpendre tornara-se audível apesar de cair com menos força, o tropear dos cavalos afasta-se (...). Num movimento rápido, (...) Raimundo Silva abriu de par em par a janela (...) e a mesma impressão de força plena e desbordante lhe tomou o espírito e o corpo, esta é a cidade que foi cercada, as muralhas descem por ali até ao mar, que sendo tão largo o rio bem the merece o nome, e depois sobem, empinadas, onde não alcançamos a ver, esta é a moura Lisboa, se não fosse ser pardacento o ar deste dia de inverno distinguiríamos melhor os olivais da encosta que desce para o esteiro, agora invisíveis como se os cobrisse uma nuvem de fumo. Raimundo Silva olhou e os tornou a olhar, o universo murmura sob a chuva, meu Deus, que doce e suave tristeza, e que não nos falte nunca, nem mesmo nas horas de alegria. [História do cerco de Lisboa, p. 116-117]

O trecho dispensa comentários. Aqui não há tão-só arqueologia, há também amor; a nenhum escritor ocorre uma personagem que desfrute a reconstituição da paisagem de "sua" cidade sem ele; este olhar, este gesto é em si característico da modernidade: que o faça Stephen Dedalus na sua torre, na estuário do Liffey, em Dublim, descortinando a linha do céu, o skyline da capital irlandesa. 
2. Acima disse "um caso de amor-ódio com a cidade". Revejo o enunciado, mudo-o: seria melhor dizer: uma relação pendular para com o fato urbano, que se traduz em obras de famílias diversas, a bem dizer opostas, sob o aspecto aqui enfocado. A primeira família acabamo-la de ver: é a que se aconchega na casa lisboeta. A ela pertencem várias de suas crônicas, entre as quais a assinalada acima, e os romances assinalados. Mas a "família" à qual pertencem Todos os nomes, Ensaio sobre a cegueira, e A caverna, e sempre considerando aqui e singularmente o fato urbano presente nessas obras, será a mesma?

No que tange à relação com o urbano, não me parece. Se a ênfase, na primeira família, está dada pelo olhar amoroso sobre o urbano, que viaja no tempo e reconstrói os teatros da civilização portuguesa tendo na Lisboa histórica o principal, na segunda a ênfase está na alegorização dos usos e abusos do poder político através da desconstrução do urbano - já não uma de uma urbe precisa qualquer, já não Lisboa, nem nenhuma outra cidade conhecida, mas do urbano como lugar do exercício do poder e, por assim dizer, de teatralização da loucura deste -. Aqui, o desamor de Saramago pela cidade desta segunda família. O aspecto "arquitextual" da operação de desmantelamento - ou, ao menos, de revisão profunda, ideológica, determinada - do urbano que Saramago procede em algumas de seus mais recentes romances, remete, a meu ver, aos contos de Objecto Quase, especialmente dois deles: "Coisas" e "Refluxo", e a O ano de 1993. Vamos a eles.

2.1. Na verdade, como já tive ocasião de apontar em outro lugar, O ano de 1993 e "Coisas" compartilham muitos aspectos, podendo ser este conto, escrito numa prosa convencional, considerado uma reescritura daquela obra, na qual o autor desenvolve uma textualidade experimental sob forma versicular. ${ }^{2}$ No primeiro, para resumir uma obra escrita com muita fluência imagética

\footnotetext{
${ }^{2}$ Cf. COSTA, 1997, cap. VI (Produção textual e experimentação em O ano de 1993 e O ouvido) e cap. VII, cit.
} 
e em níveis de significação distintos, trata-se da reconquista de uma cidade pelos seus habitantes, depois de sua expulsão por um maquiavélico e superiormente armado exército de ocupação, em termos revolucionários. No segundo, entretanto, trata-se da rebelião das coisas inanimadas de uma certa cidade - os "objetos, utensílios, máquinas e instalações", que Saramago designa paródica e cruelmente pelas iniciais, os "oumis" - que, nesta repentina e surreal antropomorfização, passam a ocupar o lugar dos habitantes da cidade, que se tinham deixado domesticar em excesso por um poder atrabiliário que lhes tinha, inclusive, tornado obrigatória na pele a incisão de seus números de identidade individuais. No final do conto, há um diálogo mantido entre um casal de "oumis" humanizados, e já vencedores de tal poder, que bem resume o sentido do relato:

Foi então que do bosque saíram todos os homens e mulheres que ali se tinham escondido desde que a revolta começara, desde o primeiro oumi desaparecido. E um deles disse:

- Agora é preciso reconstruir tudo.

E uma mulher disse:

- Não tínhamos outro remédio, quando as coisas éramos nós. Não voltarão os homens a ser postos no lugar das coisas.

(Objecto Quase, p. 109)

Graças a seus finais, tanto O Ano de 1993 como "Coisas" podem ser interpretados são exercícios éticos de positividade e revelam confiança na ação revolucionária. São, por assim dizer, alegorias, escritas em clave futurante-distópica com origem na ciência-ficção, da rehumanização de sociedades vilificadas, desumanizadas. O interessante, agora, é notar que, sob o ponto de vista do urbano, é a cidade mesma quem "personifica" o câmbio social, em "Coisas". Para tanto, ela é minuciosamente destruída, elemento a elemento, "oumi" a "oumi", e em seu lugar surge um terreno arrasado, propício à reconstrução.

2.2. Passados cerca de vinte anos da publicação desses textos, Saramago retorna ao reino do futurante-distópico com Ensaio sobre a cegueira. Discutamos a terminologia, que apliquei há pouco e com propriedade maior do que na consideração da presente orba: o 
relato de Ensaio sobre a cegeuira por certo pode ser considerado "distópico", embora talvez não tão futurante: de fato, o cenário urbano no qual se desenvolve a ação é o de hoje, e a cidade, muito provavelmente, Lisboa, embora a ausência de registros toponímicos evidentes cuidadosamente oblitere esta hipótese ao longo do relato.

Como já tive a oportunidade de apontar em outro ensaio, ${ }^{3}$ entretanto, o resultado do "mal-branco", a epidemia de cegueira que misteriosamente acomete todos os habitantes dessa cidade, menos a personagem feminina principal, a "mulher do médico", termina por levar ao completo trastocamento da ordem urbana: é num ambiente malcheiroso e violento, atulhado pelo lixo, por cadáveres insepultos, onde proliferam ratazanas, e politicamente acéfalo, que pouco a pouco o sentido da visão se restabelece, e que a população abre os olhos para um novo mundo velho. Neste relato, pouco a pouco a cidade transforma-se num labirinto no qual hordas cegas combatem-se indistintamente, selvagemente, resultando num teatro do horror que, numa espécie de pacto secreto e terrível que tão-só autor e leitor, assistidos em efígie pela sempre inquietante figura da mulher do médico, podem imaginar com propriedade.

Aqui, estamos num ambiente antipódico ao da sonolenta urbe que assiste às deambulações de Ricardo Reis, ou ao da cidadela que imagina o Sr. Raimundo Benvindo da Silva em suas contemplações crepusculares, e mesmo ao da fervilhante e semi-bárbara, barroquíssima capital do império português, cujos céus, diz-se, foram alguma vez cortados pela "Passarola" de Bartolomeu Lourenço de Gusmão, o Padre-Voador.

2.3. E que dizer da cidade do Sr. José, o kafkianissíssimo herói de Todos os nomes? Sem dúvida, a unidade mínima dessa é a labiríntica Conservatória do Registro Civil, em cujo interior tremendo guardam-se todas as fichas de todos os eventos principais vividos

\footnotetext{
${ }^{3}$ Cf. COSTA. Alegorias da desconstrução urbana: The memoirs of a survivor, de Doris Lessing, e Ensaio sobre a cegueira, de José Saramago. In: BERRINI, 1999. p. $127-148$.
} 
por todos os habitantes, mortos ou vivos, daquele país. Superarquivo, como se uma Torre do Tombo maximizada e espécie de "Vale dos mortos" do imaginário saramaguiano, o prédio da Conservatória encontra um símil não distante no orgulhoso e guloso shopping-mall simplesmente chamado "Centro" de A caverna, que engole pouco a pouco as terras ao seu redor e as transforma em multiplicantes unidades de venda ou habitação, num processo de labirintização do espaço urbano para augurar maior lucro imobiliário. Ambos, por sua vez, encontram a sua origem no conto "Refluxo", de Objecto quase, que distantemente constrói-se como uma espécie de anti-conto de fadas, e no qual é narrado o processo de transformação de um reino depois de que, sob o pretexto de livrar o país da noção de morte, o rei decide encerrar, no quadrilátero de um enorme cemitério centralizado, tudo o que no espaço dos vivos recordava a morte; entretanto, a ordem dos vivos se impõe do lado de fora dele, aonde se criam cidades de forma espontânea: "O cemitério representava cem quilómetros quadrados de quase silêncio e solidão, cercado pelo formigueiro exterior dos vivos, por gritos, buzinas, risos, palavras soltas, roncos de motores, pelo interminável sussurro das células." (Objecto quase, p. 66)

2.4. Em Todos os nomes, observamos ao ressurgimento da mesma construção imaginária, que o autor propõe à leitura como se fizesse parte do mesmo paradigma da Conservatória:

(...) Da mesma maneira que a Conservatória do Registo Civil, ainda que a correspondente informação, por deplorável esquecimento, não tenha sido dada na altura própria, a divisa do Cemitério Geral é Todos os Nomes, embora deva reconhecer-se que, na realidade, à Conservatória é que estas três palavras assentam como uma luva, porquanto é nela que todos os nomes efectivamente se encontram, tanto os dos mortos como os dos vivos, ao passo que o Cemitério, pela sua própria natureza de último destino e último depósito, terá de contentar-se sempre com os nomes dos finados. Esta evidência matemática, porém, não é suficiente para reduzir ao silêncio os curadores do Cemitério Geral, que, perante o que chamam a sua aparente inferioridade numérica, costumam encolher de ombros e 
argumentar, Com tempo e paciência cá virão parar todos, a Conservatória do Registo Civil, bem vistas as coisas, não passa de um afluente do Cemitério Geral. (Todos os nomes, p. 217-218)

A Conservatória do Registo Civil e o Cemitério Geral do Todos os nomes, assim como o Centro de A Caverna lembram-me Piranesi e seus cárceres. São como rizomas de pesadelo, ou melhor: expressões rizomáticas de uma imaginário urbano fundamentalmente marcado pela negatividade ou, pelo menos, pelo ceticismo com relação à possibilidade de que a cidade enquanto teatro do poder possa desempenhar-se autonomamente a ele, ou que nela possam os habitantes encontrar-se em liberdade. No contexto desses dois romances, as presenças dessas construções imaginárias subjugam a vida - e a morte - dos habitantes, reduzidos a sombras em seus monstruosos bojos. São, em poucas palavras, construções/expressões de desamor, e sua espacialidade não apenas metaforiza a segunda família das cidades saramaguianas: epitomizam, também, o outro lado, o lado escuro, marcado pelo labirinto, da relação de Saramago com o urbano.

2.5. Isto, em princípio. Na verdade, tanto o Sr. José de Todos os nomes quanto o simpático Cipriano Algor, o oleiro de A caverna, conseguem escapar do feitiço dessas construções algo ciclópicas. No primeiro caso, a redenção toma a forma - ou melhor, a evocação de uma mulher suicida, por quem o assustadiço burocrata se apaixona, e é precisamente no Cemitério Geral, numa noite sem lua, e ao pé da cova da sua morta, que ele encontra a paz interior e a força romper com o poder da Conservatória; no segundo, é numa assustadora visita à caverna cujo acesso é cuidadosamente vetado pelos administradores do Centro até aquele momento e que subsiste nas entranhas deste, que o artesão encontra forças para reconstruir a sua vida, já agora em termos nomádicos.

De O ano de 1993 e "Coisas" a Todos os nomes e A caverna, dir-se-ia, a rebelião de coletiva passa a ser um gesto individual, uma decisão de cada quem, a ser realizada no momento próprio e, por que não dizê-lo, epifânico, da vida de quem o leva a cabo. 
O que me interessa frisar aqui é que esta rebelião - ou esta tomada de consciência de seu poder individual, considerando o percurso do Sr. José e a transformação da vida do oleiro - se dá dentro e em função dessas construções labirínticas, que representam a aura e a ordem do poder. Na última cena de Todos os nomes, o Sr. José sai pela última vez da Conservatória do Registo Civil, assim como Cipriano Algor, em A caverna, foge do Centro e à cidade por este capitaneada. Algor chega a prever a futura comercialização da caverna em boa medida responsável pela sua revolução individual, e ao fugir da cidade o faz também da perspectiva de ter que conviver com o aviltamento da "caverna de Platão", posta à visita pelos vendilhões de plantão, os donos do Centro. Em resumo, para ambas personagens o urbano, simbolizado em tais construções, necessita ser abandonado, para que se libertem e maximizem a sua quota de humanidade. Ao contrário do significado do olhar do Sr. Raimundo Benvindo da Silva sobre o teatro da Lisboa histórica, aqui não há espaço para a aceitação: os figurantes escapam do teatro do horror, não lhes sobra outra alternativa. No caso das personagens desses dois romances, há ainda essa possibilidade: não têm, como as do Ensaio sobre a cegueira, que despertarem para um sinistro day after.

Que será menos pior?

3. Voltemos ao nosso tema. Sem dúvida, Lisboa, a real ou a irreal, ou a simultaneamente real e irreal, dá o lastre que contrabalança todas as configurações outras do urbano na obra de José Saramago. Ou serão as cidades representadas em Ensaio sobre a cegueira, Todos os nomes e A caverna elas também, sonhos - ou melhor, pesadelos -, mutações ou dimensões paralelas da Lisboa saramaguiana? E a cidade arrasada de "Coisas" e reconquistada de O ano de 1993 não serão também projeções de Lisboa, imaginadas em tardes de céu brusco, desde a Tapada da Ajuda ou da banda de Almada? E as cidades do Sr. José, da mulher do médico e de Cipriano Algor não serão, todas juntas, com a de Baltasar e Blimunda, e de Mogueime e Ouroana e de Maria Sara e do Sr. Raimundo, e de H. e M., senão uma, e variável e, ainda assim, una, Lisboa? 
Talvez nem o próprio escritor possa responder a essas perguntas. E talvez seja inútil dividir, como fiz ao longo desse ensaio, em famílias antagônicas, as cidades de José Saramago, o mais poderoso, mas não o único, habitante delas.

Se ficam essas questões - que dizer? -, muito mais ficarão as obras que as suscitaram. Procedi a alguns apontamentos que me trouxeram a elas; no processo, também me vi transitar por uma cidade saramaguiana, por qual e de quais características não está claro, mas creio em minha deambulação ter tido um portulano nas mãos.

\section{Referências Bibliográficas}

AYRES DE CARVALHO. D. João Ve a arte do seu tempo. Lisboa: Ed. do Autor, 1962. $2 \mathrm{v}$.

BERRINI, Beatriz et al. José Saramago: uma homenagem. São Paulo: EDUC, 1999.

COSTA, Horácio. José Saramago: o período formativo. Lisboa: Caminho, 1997.

FRANÇA, José Augusto. A reconstrução de Lisboa e a arquitectura pombalina. Lisboa: Instituto de Cultura Portuguesa, 1978.

SARAmago, José. Deste mundo e do outro. 2. ed. Lisboa: Caminho, 1985 (1. ed. Lisboa: Arcádia, 1971).

. O ano de 1993. Lisboa: Futura, 1975.

. Objecto Quase. Lisboa: Moraes, 1978.

. Memorial do convento. Lisboa: Caminho, 1982.

. O ano da morte de Ricardo Reis. Lisboa: Caminho, 1984.

. História do cerco de Lisboa. Lisboa: Caminho, 1989.

. Ensaio dobre a cegueira. Lisboa: Caminho, 1995.

. Todos os nomes. Lisboa: Caminho, 1997.

. A caverna. Lisboa: Caminho, 2000.

VERDE, Cesário. O sentimento de um ocidental. In: O livro de Cesário Verde; várias edições. 


\section{Resumo}

O presente ensaio visa mapear a relação de José Saramago para com a cidade. O movimento pendular da figuração do urbano em sua obra é considerado em termos contrastivos. Por um lado, estuda-se a presença da Lisboa histórica em seus escritos, de suas crônicas até alguns romances da década de 1980, nos quais uma sensibilidade para com o espaço da capital portuguesa se traduz em termos de habitabilidade imaginária no tempo histórico da mesma . Por outro, estuda-se a desconstrução da cidade em Saramago, em termos futurantes-distópicos, desde alguns contos de Objecto Quase até os seus mais recentes romances.

\section{Resumen}

El presente ensayo intenta dibujar la relación de José Saramago con la ciudad. El movimiento pendular de la figuración de lo urbano en su obra es considerado en términos contrastivos. Por un lado, se estudia la presencia de la Lisboa histórica en sus escritos, desde sus crónicas hasta algunas de sus novelas de la década de los 80s, en las que una sensibilidad en relación al espacio de la capital portuguesa se traduce en términos de habitabilidad imaginaria en el tiempo histórico de la misma. Por otro lado, se estudia la desconstrucción de la ciudad en Saramago, en términos de la distopia postulada por la ciencia-ficción, desde algunos cuentos de Casi un objeto hasta sus más recientes novelas. 